\title{
Robotic Resection of a Central Liver Solitary Fibrous Tumor (with Video)
}

\author{
Antoine Camerlo $^{1}$ D $\cdot$ Charles Vanbrugghe $^{1} \cdot$ Frederic Cohen $^{1} \cdot$ Régis Fara $^{1}$ \\ Received: 15 May 2020 / Accepted: 30 June 2020 / Published online: 15 July 2020 \\ (C) 2020 The Society for Surgery of the Alimentary Tract
}

\begin{abstract}
Background Solitary fibrous tumor is a mesenchymal tumor rare in liver parenchyma ${ }^{1}$ but must be considered as a differential diagnosis of a single large hepatic mass. Surgical resection is the treatment because of its potential malignancy, and previous interventions reported were open hepatectomy ${ }^{2}$. Robotic assets could improve accessibility for difficult liver resection ${ }^{3}$. We present the video of a robotic left hepatectomy extended to caudate lobe and median hepatic vein for central liver tumor.

Methods A central liver tumor was incidentally detected during abdominal ultrasonography in a 30-year-old man with no medical history. Laboratory tests were normal. CT scan and MRI revealed a solid mass measuring $9 \mathrm{~cm}$ involving segments I-IV-VIII and median/left hepatic veins. Percutaneous biopsy confirmed diagnosis of benign liver solitary fibrous tumor. Surgical resection by left hepatectomy extended to segment 1 and median hepatic vein was planned.

Results Da Vinci X system was docked from patient's head. Four robotic ports were placed in right hypochondrium. Two laparoscopic ports were placed for the second surgeon. Extended left hepatectomy was performed with hilar approach. Parenchymal transection was led on the right side of median hepatic vein using laparoscopic ultrasonic dissector and robotic irrigated bipolar. Segment 1 was released with a mediocaudal approach. Procedure was facilitated by good exposure of operative field with arm 4, stable vision, articulated instrumentation and a "4-hand parenchymal dissection".

Conclusion Minimal invasive resection of liver solitary fibrous tumor seems safe and feasible. Because of its advantages compared with laparoscopy, robotic approach could improve accessibility to central tumors liver resection.
\end{abstract}

Keywords Solitary fibrous tumor $\cdot$ Robotic hepatectomy $\cdot$ Central liver tumor $\cdot$ Minimally invasive liver resection

\section{References}

1. Marcelo A Beltrán. Solitary fibrous tumor of the liver: a review of the current knowledge and report of a new case. J Gastrointest Cancer. 2015 Dec;46(4):333-42.

2. Paula Novais, Carlos Robles-Medranda, Vera Lucia Pannain, Daniel Barbosa, Beatriz Biccas, Homero Fogaça. Solitary fibrous liver tumor: is surgical approach the best option? J Gastrointestin Liver Dis. 2010 Mar;19(1):81-4.
3. Liu R, Wakabayashi G, Kim HJ, Choi GH, Yiengpruksawan A, Fong Y, He J, Boggi U, Troisi RI, Efanov M, Azoulay D, Panaro F, Pessaux P, Wang XY, Zhu JY, Zhang SG, Sun CD, Wu Z, Tao $\mathrm{KS}$, Yang KH, Fan J, Chen XP. International consensus statement on robotic hepatectomy surgery in 2018. World J Gastroenterol 2019; 25:1432-1444.

Publisher's Note Springer Nature remains neutral with regard to jurisdictional claims in published maps and institutional affiliations.

Electronic supplementary material The online version of this article (https://doi.org/10.1007/s11605-020-04734-z) contains supplementary material, which is available to authorized users.

Antoine Camerlo

antoinecamerlo@gmail.com

1 Department of digestive surgery, Hôpital Européen, 6 rue désirée Clary, 13003 Marseille, France 